published in Studies in Continuing Education 2012

this version: final editorial changes not yet made

\title{
(Re/Dis)assembing learning practices online with fluid objects and spaces
}

\author{
Terrie Lynn Thompson
}

Educational Policy Studies, University of Alberta, Edmonton, Canada

\begin{abstract}
Actor Network Theory (ANT) is used to explore how work-learning is enacted in informal online communities and illustrates how researchers might use sociomaterial approaches to uncover complexities, uncertainties, and specificities of work-learning practices. Participants in this study were self-employed workers. The relational and material aspects of work-learning, along with notions of the workspace of the selfemployed as hybrid, distributed, and shifting, are considered. This study then examines the work that web-technologies, such as postings, do as they are entangled in an array of networks. Far from being singular objects unified in function, form, or effect, the posting provides multiple entry points for exploring online work-learning practices. The informal learning enacted in this study was the effect of multiple networks and attempts to stabilize fluidity. Different associations with knowledge and novel ways of knowing were also enacted, although there are contradictions between Web2.0 rhetoric and the practices of these self-employed workers. Findings suggest that practitioners and researchers should not be too quick to paint work-learning practices in online communities, or even the notion of online community, with a broad brush.
\end{abstract}

Keywords: work-learning; online communities; actor network theory; Web2.0; self-employed workers; adult education; online learning

\section{Introduction}

The connectivity possible in cyberspace brings unprecedented opportunities to engage with others for work-learning. Edwards and Usher (2008) suggest that information and communication technologies (ICT) enable new forms of knowledge production, foster new connections, and create new opportunities for learning. It is, therefore, not surprising that workers are clicking their way into all sorts of cyberspaces. Facebook, Twitter, and LinkedIn are popular social networking sites. Professional associations provide online discussion forums for exchange among colleagues. Businesses are keen to create excitement and so they support online spaces where groups of people who have bought a product or service can gather. The scale is astounding. Yahoo (2008) alone reports over 113 million members in 9 million groups. 
However, as ubiquitous web-based technologies align with people to shape cyberspaces, the accompanying hype bears examination, especially from a pedagogical perspective. Therefore, this study asks: How is work-learning enacted in online communities? Online communities appear to offer something, be it socializing, networking or support. But there is much to explore about these places as sites of learning, especially once we click outside the organized spaces attached to online courses. The notion of community is not unproblematic and an online context adds layers of complexity. This study explores the relational and material aspects of worklearning spaces online and how new ways of knowing are unfolding (or not). These insights will help adult educators and learners attend to the complexities of this form of learning.

Actor Network Theory (ANT) brings unique ways to conceptualize learning, learners, and online spaces. ANT is a philosophical orientation, not a learning theory. Nevertheless, by studying particular webs of relations, researchers can better understand the sociomaterial complexities, uncertainties, and messiness of learning practices. Because ANT emphasizes interactions between actants, things are always the effect of these networks of relations. Learners are therefore participants in networks of practices and learning emerges as an effect of the network. This relationality leads Edwards and Usher $(2008,92)$ to suggest that it is useful to articulate the learner as a 'hybrid subject shaped by other networks and flows in which they are enfolded'. If so, it is important to understand the networks and flows in which self-employed workers are engaging for work-learning.

\section{Work-Learning and ANT}

In this section, I discuss some of the current thinking on the hybrid nature of the workspace and the sociomateriality of work-learning. Workspaces are hybrid 
spaces - temporally, spatially, and relationally. Farrell and Holkner (2004) describe hybrid workspaces as a meshing of physical and virtual spaces mediated by a range of new and old communications technologies. Solomon, Boud, and Rooney (2006) see a meshing of work, social and learning spaces. In her ethnomethodological study of an airline's operations rooms, Suchman $(1996,36)$ begins with the view that the workplace is 'not so much a locale as a complex but habitual field of equipment and action, involving intimate relations of technology and practice, body and person, place and activity'. Clearly, workspaces are disparate amalgams, perhaps more so when considering the workspaces of the self-employed.

Proximities, partial fusions between people and objects, fleeting and shifting spaces: this description of the workspace and ways of working of the self-employed also applies to work-learning. As Mol $(2002,32)$ observes, knowledge is located in daily practices: 'the activities, events, buildings, instruments, and procedures'. ANT senses 'a world of partial connection in which all kinds of constantly shifting spaces can co-exist, overlap and hybridise, move together, move apart' (Bingham and Thrift 2000, 299). ANT methods thus enable exploration of the choreography of overlapping work, work-learning, and workplace spaces.

More fluid and distributed ways of working are amplified by web-based technologies. Because our work and learning activities are increasingly knit together with technologies in a rapport of shaping and adapting, it is important to attend to these relations. Waltz $(2006,58)$ argues that the 'disregard for material actors, the objectification of these actors and the overdetermination of them preclude more careful theoretical and empirical inquiry into the ways in which the persons and technologies are involved with one another'. Bigum and Rowan $(2004,219)$ posit that how to deal with humans and non-humans is 'the important consideration in any 
theorizing of innovation or the adoption of new technologies in education'. This kind of theorizing is ANT's forte.

ANT is a unique collection of relational and material understandings, concerned with associations between human and non-human actants in day-to-day practices. ANT advocates that both people and objects are legitimate research participants. And so, the technologies-in-use in an online community are not merely background, but rather, important participants also engaged in these networks. More importantly, actants (human and non-human) are co-constituted in webs of relations with other actants. An object-oriented philosophy, ANT maintains that an object is what it is because of the retinue of relations in which it is entangled. Actor-networks are thus comprised of actants that become involved in assemblages. It is because of these ties that an actor-network exists. Yet, being interconnected is not enough. The work that goes on to maintain and disrupt these connections is of interest. Through this work, Latour (1988) argues, both human and non-human actors create new sources of power and legitimacy as they renegotiate who is acting in the world, who matters, and who wants what. By attending to how actants become 'knit together', and what is circulating and mobilized in these networks, ANT is able to study provisional, black-boxed, and non-coherent practices.

Although ANT has been used widely in other disciplines, it is just making an entrée into education and learning. ANT is described as a theory, approach, method, sensibility, and/or toolkit. Recently, Law (2009a, 141) depicts ANT as a 'disparate family of material-semiotic tools and sensibilities'. He explains that ANT takes the semiotic insight that entities are produced in relations and applies this ruthlessly to all materials — not simply to those that are linguistic (Law, 1999, 4). Law $(2008,638)$ explains that ANT is the result of non-humanist and post-structuralist sensibilities 
bumping into the materially-grounded, practice-oriented tradition of Science, Technology and Society (STS).

Distinctions are often made between ANT and after-ANT. Law (2009) suggests that the new material semiotics is caught up in sensibilities such as enactment, multiplicities, fluidity, and ontological politics. Notions of obligatory passage points, centralized control, and rigid actor-networks feature more prominently in early ANT studies. Yet, Fenwick and Edwards (2010, ix) suggest that ANT's usefulness to education may well be because of its mutations into a 'highly diffuse, diverse and contested set of framings and practices'. In this study I draw on an array of ANT concepts, enacting a form of 'ANT multiple'. In many respects this is consistent with ANT itself. Neyland $(2006,43)$ suggests that instead of a fixity, ANT could be treated as 'an ongoing flow that incorporates a range of (possibly shifting) entities' and opportunities for ambiguity.

\section{Inquiry Strategies}

Participants were own-account self-employed workers (contractors and consultants who do not have staff) and selected by first employing purposive sampling through my network of contacts to 'select unique cases that are especially informative' and then snowball sampling as the initial participants suggested others that might be willing to talk with me (Neuman, 2000, 198). I focused on self-employed workers wondering if they might be more likely to turn to online communities given that they work outside the sphere of the conventional workplace and its organized learning resources.

Semi-structured interviews, which varied in length from one to two hours, were conducted with 11 self-employed workers; 10 by telephone and one face-to-face. Interviews were recorded, transcribed, and sent back to participants for verification. 
Pseudonyms are used to protect participants' identity. Follow up dialogue, either by email and/or interviews, enabled me to gather more data. Most participants also wanted to share something of their online space with me, such as postings they had made, the site 'rules', the URL of public online groups so I could see what the space was like, documents they had found about participating in a particular online community, their own website, and samples of online 'siggies' (signatures) and avatars.

Male and female participants varied in age, period of time they had been selfemployed, and the kind of work they did. They engaged in a variety of online communities, turning to these spaces at various stages in their career. While six participants had been involved for as long as five to 10 years, others had engaged for two to four years. One participant had tried several online communities in spurts over seven years and recently decided it was not for her. Technologies used included ListServs, discussion boards and forums, Yahoo groups, e-mail, blogs, and RSS feeds. Avatars, archives, FaceBook profiles, viruses, an online CV, Google, computer screens, the delete button: online learning practices are caught up in and shaped by such objects. These things were also participants in this study. Michael $(2004,20)$ argues that entities should not be spoken about. Instead, the researcher 'speaks with, by, through, and as these entities'. In this spirit I developed four heuristics researchers might employ when 'interviewing' objects: follow the actors, study breakdowns and accidents, untangle tensions, and construct co(a)gents (see Thompson, 2010a). Sørensen (2007) writes that materiality is not an essential property of an object. Therefore it is important to explore the sociality around an object as well as how people and web-technologies-in-use (such as postings) become co-constituted in online work-learning practices. In this paper, I 'interview' the posting, an actornetwork which knits an array of human and non-human entities together. 


\section{Analytical Framework}

In their study of youth literacy practices, Leander and Lovvorn $(2006,305)$ describe their analytic process as 'an interpretation of relations' shaped in a dialogue between the data and ANT. This led to an analytic framework with five dimensions, which they describe as an 'emergent, incomplete, yet productive heuristic' that they used to identify and compare configurations and circulations of objects in different activities. Using their idea of an analytic framework, I developed three ANT-inspired questions to provide some structure to my analysis: What arrays of actants and configurations are being described? How are actants brought into relationship with each other? What is circulating between actants in the enactment of informal work-learning? Several sub-questions deepened the analysis and included: What passages are (dis)ordering relations? What ongoing negotiations maintain or upset network continuity? What social practices are occurring around objects? This framework was then applied to a series of anecdotes developed from the data about learning practices. As Law (2009b, 2) argues, 'practices are assemblages of relations', therefore, attention is needed to discern patterns of relations and how these relations get assembled.

\section{(Re/Dis)Assembling}

This paper focuses on how work-learning is being enacted. See Thompson (2010b) for an extended discussion of the kinds of learning that unfolded in these cyberspaces. Briefly, in addition to learning things that helped them with day-to-day work activities, participants were learning more about particular practices as well as the viability of certain work. They were also figuring out how to draw on and participate in fluid and mobile knowledges. A surprising amount of learning was focused on developing skills related to learning in these online spaces.

Engaging in an online community for work-learning merges self-employed workers into menageries of other people, objects, ideas, actions, and invocations. 
Learning practices keep these continually shifting configurations in motionassembling, dis-assembling, and re-assembling. How does a researcher begin to understand these fluid assemblages? Latour (2005) advocates 'following the actors', noticing what an actor - either human or material — is compelling other entities to do. Callon (1987, 93 emphasis added) explains that 'an actor-network is simultaneously an actor whose activity is networking heterogeneous elements and a network that is able to redefine and transform what it is made of '. Many actor-networks are involved in the informal work-learning practices in an online community. I begin with the posting. As the data in the next section illustrates, postings are taken up as different objects in different networks as they circulate in whole or in part, on predictable paths or unexpected trajectories, gaining momentum or sputtering into oblivion. I turn to several ANT concepts to better understand the posting as an actor-network. It is also necessary to attend to how materialities around the posting are performed relationally and I will share data that helps explore relational dimensions.

\section{The Posting}

The data describes a posting as usually text, often accompanied by attachments or weblinks, and sometimes embedded with graphical and animated elements, even viruses. It moves via a web-based conduit as part of a thread in a discussion forum, an RSS feed, an e-mail message, or blog comment and ultimately appears on a computer, cell phone or iPod screen. Postings are fluid in time and space — read in seconds, minutes, or days after they have been written. Some postings are valued and others regarded as a nuisance. Some are amusing, others intimidating. A number arrive heralded by music and flags. Many slip into oblivion in cluttered Inboxes or forums. Along the way, a few may acquire ratings. Fingers hover over the delete button as the subject line, author, and the clock are consulted before time is 
spent with the posting. Many are deleted or glossed over without a second glance.

Others are savoured, read intently, and saved. Postings are written with expectations of readers, responses, and reciprocity. Indeed, the collection of postings in an online space provides a public barometer of the richness, visibility, and viability of an online community. Postings and responses traverse from one-some-many to one-some-many linking colleagues, strangers, competitors, lurkers, the online paparazzi.

Participants indicate that it is important to have a good configuration of actants - people, expertise, and technologies — in order to benefit from the best possible knowledge. Reading, composing, or replying to a posting is seemingly done to bring a configuration of actors into play. Postings enrol other actants and are used by both human and non-human actants for this purpose. A posting requires a network of allies in order to circulate. But not all entities in this network are faithful intermediaries. Many entities, including the posting, are mediators, changing meanings, elements, and configurations. Latour $(2005,39)$ explains that mediators transform 'the meaning or the elements they are supposed to carry'. In contrast, an intermediary is like a black box, transporting meaning without changing it.

\section{(Im)Mutable mobiles.}

Two ANT concepts explain how it is possible for postings to be both mediators and intermediaries. Some objects may be described as immutable mobiles: objects which maintain their form as they travel (Latour 1990). A posting is an immutable mobile. It is easily packaged into online missives which can be distributed globally in the blink of an eye and also tagged and archived for future readers. Law and Singleton (2005) refer to immutable mobiles as network objects: mobile while also holding their shape in a network of relations. 
But a posting is also more fluid than this. It can change as it moves. Ryan, an occupational health consultant, is rattled when a snippet of a posting he made — in what he thought was a private forum for health professionals - comes back to him with questions about how he got this information:

I was talking about a particular worker and I mentioned the workplace ... I can talk to another nurse or physician about a patient ad nauseum and know they are bound by their professional guidelines. Not so with others .... Sometimes when you post a message you never really know where it's going to end up.

A posting's compact digitized form makes it easy to share and modify. Ryan's posting is changed so only a certain paragraph circulates. It becomes a mediator, changing meanings, and things do not go as planned. Postings do not always stay intact and are not necessarily read only by those for whom they are intended.

An example from the literature manifests a similar kind of fluidity. In their study of the Zimbabwe bush pump, de Laet and Mol (2000) describe the bush pump as a changeable object that is not too rigorously bounded and so is adaptable and responsive. The bush pump changes shape (bits and pieces fall off or are added) and works in different ways in different villages. Leather seals are replaced by old tyres, bolts by steel bars, and yet it keeps operating. Law and Singleton (2005) use this example to argue for the notion of a fluid object, which they also call a mutable mobile: an object as a set of relations that gradually shifts and adapts rather than holding itself rigid.

The posting is therefore also a fluid object, a mutable mobile. It shifts and adapts as it gets entangled in other networks. Participants describe how it can be taken up in different media: posted on a website, archived, buried in an Inbox, printed on paper. It can be carved into snippets and re-distributed. It can be divorced from the context in which it was written, the sender's name and even the thread in which it was composed, obscured or removed. A posting is both constant and fluid. It may be 
suspended in a stable network of relations or change shape gradually as the relations around it shift too. It is possible that some of the postings in this study may even be what Law and Singleton (2005) term fire objects: objects that jump and are discontinuous. Perhaps the snippets of Ryan's posting that re-circulate in different networks are more suddenly and markedly different rather than a gradual re-shaping. Nevertheless, both fluid and fire objects, according to Law and Singleton, are spatial forms that are different and yet partially connected.

\section{Only in Relation}

By 'following' the posting, one can see that it is both an immutable and mutable mobile, entangled in an array of actor-networks, and often enacted differently in different assemblages. The focus now shifts from interconnections to circulations. Latour (2005) emphasizes that it is the work going on within the networks that is of interest. How do relations between actants in these online work-learning assemblages come to be and what is circulating within these conduits? I return to the posting to see what work it is doing.

Amy expects more in-depth discussion in her online group and makes postings to try to get other sport psychologists talking about overlooked topics. Mia wants a 'community by distance' and enlists avatars and online aliases she does not use anywhere else in order to maintain a high degree of anonymity. Here, postings are purposefully aligned with other actants in order to achieve a purpose, be it a different level of discussion or increased anonymity. For Amy, her postings are attempts to engage other colleagues in order to expand the network of participants and to change the content that is circulating. For Mia, postings are linked to other objects to create a screen so she can explore new conversations without others in her current professional network knowing. 
Postings may also be traces left in cyberspace to bump into other objects and people. Mia comments, 'the way you select what you're interested in, connect your blog to others, your deli.cio.us tags to resources, defines your interests and who potentially may be interested in linking to you'. These traces form webs in cyberspace. Texts such as postings, which continue to float - to be enrolled into new configurations - create opportunities for sustained engagement. But in two instances participants hesitate because they do not want to stay connected with their posting. They want to disconnect from the network and what is circulating. Liz explains:

\footnotetext{
You make one posting but it lives on in time and you may find yourself having to continue to attend to the fallout. ... Sometimes if you post something and you have people coming back with questions and more questions you have to keep posting. You can't just make one post and say that's it.
}

Postings are therefore juxtaposed with other actants in different ways to foster both presence and absence. Some participants describe how they become enrolled in online communities through the 'wow' factor and strength of a particular actornetwork: the 'big names' and the richness of technical features and tools. Forums without a lot of new postings look tired and do not enlist new actants. Well maintained archives and up-to-date resources, on the other hand, do. Sophie's group enrols objects such as the ListServ, the search engine, and archived postings to simplify the process of welcoming newbies. The online community is thereby kept fresh: a circulation highly valued by the workers in this study. Postings link both presence and absence. Law and Singleton $(2005,343)$ assert that 'an object is a pattern of presences and absences'. This is true of postings. Postings plus the presence of an array of the 'right' actants creates a buzz and attract others. Postings also become 'stand-ins', helping to enrol people in online conversations by compensating for absent actants such as the water cooler or physically co-located co-workers. 
So far, postings can be both immutable and mutable mobiles. Postings can (re)configure online spaces and interactions. A posting is a performance. But it is only a performance because it is enacted in a network of relations with other actantshumans and non-human. In so doing, postings help to enact work-learning practices.

The notion of translation is useful here. According to Callon $(1986,26)$, translation is a 'definition' and 'distribution' of roles and the 'delineation of a scenario' which 'establishes more or less stable relationships between entities'. The data illustrates how postings are translated into indicators of the liveliness of an online community or translated into online breadcrumbs that wait for others to stumble across them. As a posting moves in and out of different actor-networks it is implicated in attempts to order and dis-order. For example, the data above shows how postings are used by self-employed workers in attempts to (re)configure online spaces to achieve the sense of community most conducive to their purposes: extending the network, changing the discussion, or creating screens to ensure privacy. These are endeavours to order and work-learning becomes 'an achievement, a process, a consequence, a set of resistances overcome, a precarious effect' (Law 1992, 390).

It is now clear that the posting-object is a multiplicity; not confined to one space and time. In different networks, postings do different things: materiality is shaped by relationality. The posting is often considered the cornerstone of online discussion and learning. Yet, this analysis highlights how many different things a posting is and does. Learning in online communities is not always as simple as posting a question or reading a reply — there are more detours and bumps to consider.

\section{Enacting Informal Learning}

The learning practices of these workers are enactments: 'occasion[s] in a location, a set of actions with a series of effects' (Law 2000, 349). In this section, I explore how 
informal learning practices are enacted by taking a closer look at the work-learning practices in which the posting (and other actants) circulate and the kinds of work these actants are doing in those practices. Specifically, I will explore how workers both welcome and try to contain fluidity and also the effect of multiple networks. I then turn to how ways of knowing take different forms in various enactments of 'online community'.

\section{Stabilizing Fluidity}

Participants indicate that they want fluidity in how they engage in their online communities. The anywhere-anytime promise of the Internet appeals and suits ways of working. Yet, they also want to learn efficiently and to do so, some stability and predictability from the technologies-in-use and practices within the online community are needed. Young $(2006,260)$ found that actors in his study tried to 'counter complexity by seeking out and establishing stable and predictable arrangements with persons, organizations, and technologies'. This takes work. Suchman $(2007,21)$ argues that 'despite the seeming automaticity of relations, they do not run by themselves but must be continually reiterated and reproduced'.

The data offers insights into how workers in this study are constantly renegotiating relations. Although the human actants take a strong role in keeping actor-networks aligned, objects are volunteered, or even step in, to do this. For example, digests of the day's postings, which arrive regularly in an Inbox, are one attempt to routinize engagement. Technology is enrolled to faithfully transport a compilation of people's contributions. Digests 'translate' online conversations in order to make it easier for people to stay engaged. But they are disjointed and not characteristic of how a discussion unfolds. Amy declares, 'If you just check in once a 
week and suddenly you respond to everything, you're not really discussing. You're putting your input in after the conversation is done.'

Here again, the posting is a fluid object, changing as the network of other actants around it changes. Each shift, from dialogue to digest and back again, is a translation, which necessarily entails recruiting other actants. When postings are packaged into the digest version, conversations are translated into snippets. Therefore, additional actants, such as the archives, must be recruited to re-construct the dialogue. Digests might be more convenient if you wish merely to scan postings, but more difficult to manage if you wish to engage. Sophie explains:

You can get a digest ... but that's a bit more challenging because you don't get them in order of the time they arrive. You might follow a conversation from $\mathrm{A}$ to $\mathrm{D}$ to $\mathrm{B}$ to $\mathrm{C}$ and go, OK, I think I've got that. If it's important to get it you can always go into the archives.

Although the digests are a popular time saving strategy and provide some measure of 'discipline' by conveniently arriving at the same time every day, several participants comment that they feel more engaged when getting the actual messages.

Signing up for the digest version is sometimes an indication that engagement is on the wane. If so, the posting in 'digest' version has a weaker ability to enrol other actants.

\section{An Effect of Multiple Networks}

Because actor-networks do not stay put in cyberspace, these networks are not space and time-bound. Objects, such as postings, are not the only actants caught up in multiple networks. When Amy, a sport psychologist, needs to create a race plan for running injured in the Boston Marathon, she makes a posting. One response is especially valuable. She shares:

That e-mail [posting] helped me re-conceptualize what I was thinking when I went into the race. I'm not sure it really all set in until I was running the race. Then I think I got what he was saying, which I hadn't really got beforehand.

A deeper learning is felt a few years later when she starts teaching running seminars and helping others in similar situations. For Amy, learning is the effect of several 
networks: the online space, the assemblage of the marathon, and a running seminar. The enactment of this learning is made durable once it is brought into networks other than the one she instigated in the online community.

These are not merely sequential networks. As Latour (2005) argues, any interaction overflows with ingredients from other times, spaces, and agents and these can be traced. ANT attends to the local and the particular. When Amy counsels another runner about how to run a race when injured, ingredients are drawn into this network from other configurations that reflect different places, spaces, and times: her injury, the SportPsych ListServ, the posting she received, the Boston Marathon. Nespor $(1994,21)$ writes that as 'people stretch out in many directions at once and intertwine with other people and things distant from them', the effect is 'knowledge in motion'. Actor-networks can thus become richer and more layered as knowledge circulates. Online communities are not singular networks. Work-learning does not unfold in stand-alone networks.

Although multiple networks can enrich the learning possibilities, as in Amy's case, sometimes they create unwelcome complexity. Aanestad (2003) writes that the extension of the network intensifies network dependencies. The learning practices described by these self-employed workers point to attempts to extend the network by reaching out to many more human actants and being tied into numerous technologies (objects). Inter-dependencies become more complex, which may help to explain both the resiliency and fragile nature of an online community. However, expanding a network can create an unwieldy entity. Liz explains why she is less engaged in online communities: 'Viruses, spyware, Trojans, spam, commercialization (business sites that write scripts to change your home page) means a computer connected to the Internet now has higher demands in terms of maintenance. The cost-benefit balance 
has shifted.' Work-learning practices entail a constant assessment of return on investment of one's time and energy. Liz does not welcome the many unwanted, demanding, and labour-intensive objects linked to internet security. Spending more time online translates into enrolling more technology objects - extending her network and dependency on other elements - in order to fight off unwanted entrants such as viruses, spyware, and spam. For Liz, stabilizing fluidity is achieved by opting out of the network. It was overloaded; one network too many.

\section{Knowledge Associations: Ways of Knowing}

'Following' the posting has afforded insights into several sociomaterial negotiations assembling the practice of work-learning online. I return to the posting to further explore how participants associate with circulating knowledges and the implications of these associations for the enactments of knowing and learning. Both Amy and Dorothy turn, in different ways, to online communities via postings, to solve worklearning needs.

Amy is using Adobe Professional to create an electronic form and encounters an issue. She goes to the Adobe forums:

\footnotetext{
No one answered my question but reading through the discussion forums I solved my problem. There was obviously a core group of people. For them I would say this was a community where they went for help and it helped them in their jobs. ... I popped in and out. ... I was expecting that I would post my question and within an hour I've got a whole bunch of answers from all these brilliant people. That wasn't the case. But I went in there with a purpose and I came out with my problem solved. I would never say, "Oh yes, I'm part of that community."
}

Dorothy has run a home-based daycare for 12 years and is a moderator on a small close-knit online community of other daycare providers. It is right after lunch and the children are napping. She does not know what to do with one of them:

She's biting me and throwing poop at me. I am almost bawling my eyes out on in this post: "I don't know what to do. Is it me?" The responses start to come back in 10 minutes. "Don't beat yourself up. You know she needs special care." At that moment I realized, "I can't fix everybody and I have to protect the kids that are in my care." And they just made me feel like that's normal. It's not you, it's the situation and you've got to do something about it. I really value this support. Here's me with all this experience 
going why can't I deal with this kid? ... The group can talk to each other in real time to chat but we don't. We'll post. The conversation goes on during most of nap time because by then a few of the others have logged on. When someone's in a real crunch like I was, people don't get off their computer. They sit and talk. I'm wondering, "How should I tell the dad?" Throughout the week the group helps me compile a letter saying that this little girl's needs go beyond my capabilities and she might need a special caregiver. By Friday, the letter is drafted and I give it to the child's father.

These anecdotes describe different ways of knowing. Amy needs help and poses her question to an online group that will know best. Although she does not get a direct response (her posting does not mobilize other actor-networks), she finds the information in their archived discussions. For Amy, these 'found' postings are 'pieces' of valued information she can use elsewhere. In contrast, Dorothy has been in a tight-knit group for years. Faced with an issue, she works with her online community to construct an understanding of how to handle a difficult situation, a dialogue which also builds their collective practice as daycare providers. For Dorothy, the value of a posting emerges from the process of how it comes to be and what it evolves into as others add to it and move it along. The posting blossoms into a conversation, a problem solving session, and a way others support and coach her. A letter is produced and becomes part of the assemblage. Yet, even though the posting is enacted in the practices of this online space, anyone can come along next week, read it, and take it into their own space, as Amy did when she visited the Adobe group.

Mol $(2002,43)$ argues that objects have a complex present 'in which their identities are fragile and may differ between sites'. Similarly, as the data in this study has illustrated, postings are fluid objects and may take various forms. Imagine that Dorothy did not go through the process just described. What if someone else, say Fran, had turned to her online community and engaged with them to figure out how to tell a father she is not equipped to care for his child. Imagine now that Dorothy realizes she too has this problem, but instead of turning to a close online community, she searches on the Internet and voila finds Fran's discussion group, complete with 
Fran's postings, the responses of the others, and the draft letter. In this scenario, the posting that Dorothy comes across is not the same as the one Fran created - it enacts a different reality. One reality is finding a useful posting in the archives of an online group. Read in a different space and time from which it was composed, it is a record of a conversation that is subsequently 'harvested'. The other reality is enacted through an online dialogue; the postings and the circulations they mobilize stay tightly knit to a particular network of people and objects — for awhile. These are not the same objects but rather, two partially connected objects ensnared in two different sets of relations.

Returning to Amy and Dorothy's original stories, the posting, to use Law's $(2004,55)$ phrase, is not the same object but rather, 'different objects produced in different method assemblages'. Mol's (2002) analysis of atherosclerosis provides a vivid example of how this is possible. She describes atherosclerosis as two objects, one enacted through talk between a patient and physician in an interview in the outpatient clinic and the other through a physical examination of the patient by the vascular surgeon. She explains that the difference between these two locations 'may not attract attention as long as the objects they enact coincide, but as soon as they contradict each other, it becomes apparent that the clinic is two places. The interview. And the physical examination' (Mol 2002, 51). The same realization applies in this study of work-learning practices online. Some workers will drop into an online space to harvest postings. Others will go through a dialogic process to build these online conversations with others. The fact there are different enactments is not always problematic, but sometimes the differences highlight contradictions, such as tensions between Web2.0 rhetoric and practice. 


\section{Contradictions in Online Learning Practices}

Much has been written about how Web2.0 is leading to more networked ways of living, working, and learning. The most heralded shift is a re-positioning of people from consumers to producers of information and knowledge. In this view, the emphasis is on creation rather than consumption of information, collective intelligence that harnesses the power of the crowd, decentralisation of content and control, and fostering of communities (Anderson 2007; Downes 2007). Yet, in this study, participants frequently found information in an online forum and treated it no differently than 'static' information on a web site. Does this reflect the rhetoric of new ways of learning and knowing online?

Haythornthwaite $(2008,599)$ argues that information is too often treated as 'a static, one-off, unchanging token'. She adds that 'ideas of easy access [to information in online forums] become far more problematic ... when the knowledge to be retrieved entails practices, argumentation, and evolution instead of simple retrieval of data bits'. Hemetsberger and Reinhardt (2006) agree: it is often the line of argument, not the content, which provides the most valuable insights. Neyland $(2006,35)$ explains that although information is often regarded as an extant thing, which can be passed along while still retaining the same identity, his study of university strategy processes suggests that the flow of information 'could be conceptualized as a series of sociotechnical connections, each connection forming an opportunity to confirm the continuity of information usage or to reconstruct ... the information itself'.

In this study of self-employed workers, information and knowledge is treated, at times, as a 'thing' that is transferred, rather than a dynamic circulation within an online configuration. Hence, the common practice of harvesting pieces of information. Pels, Hetherington, and Vandenberghe $(2002,11)$ state that facts become 'thinglike entities [when] actors fail to calculate their own performative contribution to them and 
continue to treat them as things'. The data in this study confirms these practices. However, this actor-network analysis also shows that networks are multiple and not bound to cyberspace. Although workers 'take' from an online community, they often then shape this knowledge - continue their learning — in their own work and workspaces, including interactions with others offline. As Neyland (2006) suggests above, in these instances, knowledge may not be treated as an extant thing, but rather this movement into a person's workspace is an opportunity to affirm the continuity of, or to reconstruct, the information. However, such actions are not seen in the public spaces of an online community and would be interesting to trace in future research.

The notion of multiplicities calls attention to the different sociomaterialities of an online space. In Dorothy's work-learning practices, the posting stays enmeshed in the actor-network (aka online community) as it develops. This online space and the actors within it, such as the posting, take on specific materialities as Dorothy's learning and learning space, her work and workspace. In Amy’s sociomaterial organization of work-learning practices, the posting shifts out of the Adobe forum into another configuration closer to her work and workspace, losing and gaining actants in the process. As the posting sheds some of the trappings of the Adobe forum, it must then be juxtaposed with other actants more aligned with her work and workspace. Amy's brief foray into the Adobe forum does not imbue that forum with the materiality of being her learning and work space in the same way that Dorothy's extended interactions do.

In her exploration of multiple ontologies, Mol $(1999,79)$ writes that a disease takes various forms that cannot merely be described as perspectives seen by different people. Rather, they are 'different versions, different performances, different realities, that co-exist in the present'. Similarly, ways of knowing in this study take different 
forms. Amy and Dorothy do not do different things to arrive at the same outcome. Different 'socialities' around a posting and its different materialities leads to the enactment of different work-learning practices. But despite these different objects, assemblages, and practices, the net effect is learning for both Amy and Dorothy.

\section{Conclusion}

One appeal of online communities to the workers in this study was their potential richness for learning. Findings are consistent with Mulcahy's (2005, 3) observation that 'education becomes an accomplishment of a network rather than an individual' and as such, the relations between actors and the way some entities circulate is critical to what unfolds. The relations that connect these self-employed workers to other actants count. Compared to a Google search, for instance, this is a different way of being online and a different practice of relating to knowledge even though many of the same actants (i.e., web-based objects) are implicated. The negotiations between these different materialities are paramount for understanding the assemblage of relations that comprise work-learning practices online.

I explored how the posting was implicated in a vast array of actor-networks (re/dis)assembling in the pursuit of work-learning. Fluid objects creating fluid spaces lead to sinuous practices. Online communities are not containers for online activities but rather networks of relations in constant flux. There is no one way that learning is done in online communities. Rather, these practices depend on a continued crafting of people, techniques, texts, technologies (borrowing from Law, 2004), including the continued shaping of online community as a complex actor-network. ANT is wellsuited to explore how these practices are far from being a seamless or singular experience. Rather, these practices reflect multiplicities and remind adult educators about the importance of attending to the complexities of this form of learning. 
For example, in his exploration of collective learning, Law (2007) concludes that patching practices together takes patience, effort, and work. Amy has to work at this, just as Dorothy does. Perhaps Amy has to work even harder as she choreographs bits and pieces from all over. The postings she uses do not constitute her learning and work space in the same way they do for Dorothy. Law explains that some of the pieces in his learning space belong to, redo, extend, and translate practices done elsewhere. But because they also belong to 'elsewhere' practices, there are tensions and ambivalences, which need to be better understood.

This study also suggests that adult educators and researchers should not be too quick to paint work-learning practices in online communities, or even the notion of online community, with a broad brush. The posting is often taken for granted; it has become (in Latour's (2005) words) a matter of fact, not a matter of concern. Yet, this analysis highlights how many different things a posting is and does and raises new questions about work-learning.

Terrie Lynn Thompson recently completed her PhD in the Faculty of Education at the University of Alberta (Canada) and is doing post-doc work at Athabasca University. She is also the "researcher-inresidence" for an international NGO focused on ICT for social and economic development. Research preoccupations include work-related learning in all kinds of online communities, the politics and ethics of ICTs, exploring how web-based technologies can facilitate social development, and informal learning.

\section{References}

Aanestad, M. 2003. The camera as an actor: Design-in-use of telemedicine infrastructure in surgery. Computer Supported Cooperative Work 12, no.1: 120.

Anderson, P. 2007. What is Web 2.0? Ideas, technologies and implications for education (JISC Technology and Standards Watch). JISC website. http://www.jisc.ac.uk/media/documents/techwatch/tsw0701b.pdf

Bigum, C., and Rowan, L. 2004. Flexible learning in teacher education: Myths, muddles and models. Asia-Pacific Journal of Teacher Education 32, no. 3: 213-226. doi:10.1080/1359866042000295389

Bingham, N. and Thrift, N. 2000. Some new instructions for travellers: The geography of Bruno Latour and Michel Serres. In Thinking space, ed. M. Crang and N. Thrift, 281-301. London, England: Routledge.

Callon, M. 1986. The sociology of an actor-network: The case of the electric vehicle. In Mapping the dynamics of science and technology: Sociology of science in 
the real world, ed. M. Callon, J. Law, and A. Rip, 19-34). Houndmills, England: The Macmillan Press.

Callon, M. 1987. Society in the making: The study of technology as a tool for sociological analysis. In The social construction of technological systems: New directions in the sociology and history of technology, ed. W.E. Bijker, T.P. Hughes, and T.J. Pinch, 83-103. Cambridge, MA: MIT Press.

De Laet, M., and Mol, A. 2000. The Zimbabwe bush pump: Mechanics of a fluid technology. Social Studies of Science 30, no.2: 225-263.

Downes, S. 2007. Learning networks in practice. In Emerging technologies for learning (Vol. 2, pp. 19-27). Becta website.

http://partners.becta.org.uk/index.php?section=rh\&\&catcode $=\&$ rid $=13904$

Edwards, Richard, and Usher, Robin. 2008. Globalisation and pedagogy: Space, place and identity $\left(2^{\text {nd }}\right.$ ed.). Milton Park, England: Routledge.

Farrell, L., and Holkner, B. 2004. Points of vulnerability and presence: Knowing and learning in globally networked communities. Discourse: Studies in the Cultural Politics of Education 25, no. 2: 133-144. doi:10.1080/01596300410001692111

Fenwick, Tara., and Edwards, Richard. 2010. Actor-network theory in education. London, England: Routledge.

Haythornthwaite, C. 2008. Ubiquitous transformations. Proceedings of the 6th International Conference on Networked Learning, 598-605. http://www.networkedlearningconference.org.uk/past/nlc2008/Info/confpapers .htm\#Top

Hemetsberger, A., and Reinhardt, C. 2006. Learning and knowledge-building in opensource communities: A social-experiential approach. Management Learning 37, no. 2: 187-214. doi:10.1177/1350507606063442

Latour, Bruno. 1988. The Pasteurization of France (A. Sheridan and J. Law, Trans.). Cambridge, MA: Harvard University Press.

Latour, Bruno. 1990. Drawing things together. In Representation in scientific practice, ed. M. Lynch and S. Woolgar, 19-68. Cambridge, MA: The MIT Press.

Latour, Bruno. 2005. Reassembling the social: An introduction to actor-network theory. Oxford, England: Oxford University Press.

Law, J. 1992. Notes on the theory of the actor-network: Ordering, strategy, and heterogeneity. Systems Practice 5, no. 4: 379-393.

Law, J. 1999. After ANT: Complexity, naming and topology. In Actor network theory and after, eds. J. Law and J. Hassard 1-14. Oxford, England: Blackwell Publishers.

Law, J. 2000. Comment on Suchman, and Gherardi and Nicolini: Knowing as displacing. Organization 7, no. 2: 349-354.

Law, John. 2004. After method: Mess in social science research. Milton Park, England: Routledge.

Law, J. 2007. Pinboards and books: Juxtaposing, learning, and materiality. In Education and Technology: Critical perspectives, possible futures, ed. D.W. Kritt and L.T. Winegar, 125-149. Lanham, MD: Lexington Books.

Law, J. 2008. On sociology and STS. The Sociological Review 56, no. 4: 623-649. doi:10.1111/j1467-954X.2009.01846.X

Law, J. 2009a. Actor network theory and material semiotics. In The new Blackwell companion to social theory, ed. B. S. Turner, 141-158. Chichester, England: Wiley-Blackwell. 
Law, J. 2009b. Collateral realties. http://heterogeneities.net/publications/Law2009CollateralRealities.pdf

Law, J., and Singleton, V. 2005. Object lessons. Organization 12, no. 3: 331-355. doi: $10.1177 / 1350508405051270$

Leander, K.M., and Lovvorn, J.F. 2006. Literacy networks: Following the circulation of texts, bodies, and objects in the schooling and online gaming of youth. Cognition and Instruction 24, no. 3: 291-340.

Mol, A. 1999. Ontological politics. A word and some questions. In Actor network theory and after, ed. J. Law \& J. Hassard, 74-89. Oxford, England: Blackwell Publishers.

Mol, Annemarie. 2002. The body multiple: Ontology in medical practice. London, England: Duke University Press.

Mulcahy, D. 2005. Between work and learning: On pedagogic practice and interstitial space. In $4^{\text {th }}$ International Conference on Researching Work and Learning, ed. P. Hager and G. Hawke, Sydney, Australia: University of Technology Sydney. http://www.projects.education.uts.edu.au?RWLY/conf-results.lasso

Nespor, Jan. 1994. Knowledge in motion: Space, time and curriculum in undergraduate physics and management. London, England: The Falmer Press.

Neuman, W. L. 2000. Social research methods: Qualitative and quantitative approaches $\left(4^{\text {th }}\right.$ ed.). Boston, MA: Allyn and Bacon.

Neyland, D. 2006. Dismissed content and discontent: An analysis of the strategic aspects of actor-network theory. Science, Technology \& Human Values 31, no. 1: 29-51. doi:10.1177/0162243905280022

Pels, D., Hetherington, K., and Vandenberghe, F. (2002). The status of the object: Performances, mediations, and techniques. Theory, Culture \& Society 19, no. 5/6: 1-21.

Solomon, N., Boud, D., and Rooney, D. 2006. The in-between: Exposing everyday learning at work. International Journal of Lifelong Education 25, no. 1: 3-13. doi:10.1080/02601370500309436

Sørensen, E. 2007. The time of materiality. Forum: Qualitative Social Research 8, no. 1. http://www.qualitative-research.net/index.php/fqs

Suchman, L. 1996. Constituting shared workspaces. In Cognition and communication at work, ed. Y. Engeström and D. Middleton, 35-60. Cambridge, England: Cambridge University Press.

Suchman, Lucy. 2007. Human-machine reconfigurations: Plans and situated actions $\left(2^{\text {nd }}\right.$ ed.). Cambridge, England: Cambridge University Press.

Thompson, T. L. 2010a. Assembly required: Self-employed workers' informal worklearning in online communities. $\mathrm{PhD}$ diss., University of Alberta.

Thompson, T. L. 2010b. Self-employed and online: (Re)negotiating work-learning practices. Journal of Workplace Learning 22, no. 6: 360-375. doi:10118/13665621011063478

Waltz, S. B. 2006. Nonhumans unbound: Actor-network theory and the reconsideration of "things" in educational foundations. Educational Foundations 20, no. 3/4: 51-68.

Yahoo. (2008, May 28). Blog, Think big. Think purple. http://www.ygroupsblog.com/blog

Young, N. 2006. Distance as a hybrid actor in rural economies. Journal of Rural Studies 22, no. 3: 253-266. doi:10.1016/j.jrurstud.2005.11.007 